\title{
ANTHROPOLOGICAL PERSPECTIVES ON NATURAL RESOURCES MANAGEMENT, CLIMATE CHANGE AND GLOBAL WARMING: FROM QUANDARY TO ACTIONS
}

\author{
Dr. Prakash Upadhyay (Nepal)
}

\begin{abstract}
Anthropology brings its core theoretical tenet that culture frames the way people perceive, understand, experience, and respond to key elements of the worlds which they live in. This framing is grounded in systems of meanings and relationships that mediate human engagements with natural phenomena and processes including climate change. Anthropology's potential contributions to natural resources, climate and global warming researches are the description and analysis of the mediating layers of cultural meanings, norms and social practices, which cannot be easily incarcerate by methods of other disciplines. There are vital key contributions that anthropology can bring to understandings of climate change. The foremost is awareness to the cultural values and political relations that shape the production and interpretation of climate change knowledge and shape the basis of responses to ongoing environmental changes as ecological colonialism. Anthropological knowledge is holistic-referring to the study of the whole of the human condition: past, present, and future; biology, society, language, and culture. Climate change is ultimately about culture, for in its wake, more and more of the intimate human-environment relations, fundamental to the world's cultural diversity. Anthropological lens cram to learn about human significance of climate change by studying the manner and the knowledge system of people in different cultures and communities to understand to the new threats of climate change, global warming and the local responses to tackle the menace. Through anthropological lenses on the scale of global geopolitics, anthropologists perceive the causes and effects of climate change to be about people and their life, survival, power, ethics and morals, environmental costs and justice, and cultural and spiritual endurance with a perception Raise Your Voice Not Sea Level.
\end{abstract}

KEYWORDS: Integrative approach, paradigms, periphery, biotic, anthropogenic, livelihood

\section{INTRODUCTION}

Sustainability of natural resources is imperative for the survival of human being. There are various actors and factors that guarantees and hinders the sustainability of natural resources. According to Berkes and Farvar (1988) sustainability of natural resources is hindered by an assortment of issues. However, scientific and technological approaches to natural resources management often 
fail to encourage sustainable resources management because they are based on faulty model, limited goals, incomplete information, and an inadequate institutional foundation.Traditional resources management systems, in contrast, often derived over time through a process of cultural learning, are frequently successful (Ostrom 1990). Knowledge of an integrative approach based on lessons from traditional systems combined with adaptive natural resources management theory could be more helpful by providing a richer basis for the analysis of institutional innovation while integrating local knowledge and monitoring into resources co-management. Co-management is more likely to lead to the local knowledge, scientific resources management, and institutional adaptability to local conditions and change for resources production. There is an urgent need for an assessment of indigenous resources knowledge and management goals, and better understanding of existing paradigms, social structures, political organization and knowledge dispensation in the field of natural resources management, climate change and global warming nexus for which anthropological knowledge is imperative. In the last few years, anthropologists are caught up in climate change and global warming research to an unprecedented degree. Three conditions are responsible for this development: the irrevocable transformations that climate change is bringing to the people and places traditionally studied by anthropologists (Boko et.al. 2007), the general recognition of the importance of research on the human dimensions of climate change (Vogel et.al. 2007), and the growing opportunities for anthropologists to participate in interdisciplinary climate application and adaptation research (Roncoli 2006). To this challenge anthropology brings its core theoretical tenet: that culture frames the way people perceive, understand, experience, and respond to key elements of the worlds which they live in. This framing is grounded in systems of meanings and relationships that mediate human engagements with natural phenomena and processes. This framing is particularly relevant to the study of climate change and global warming that necessitate movement away from a known past, though an altered present, and toward an indecisive future, since what is recalled, recognized, or envisaged rests on cultural models, norms and values. Human being and collective adaptations are fashioned by common ideas about what is believable, desirable, feasible, and acceptable by the majority. Anthropology's potential contributions to natural resources, climate and global warming researches are the description and analysis of the mediating layers of cultural meanings, norms and social practices of the majority, which cannot be easily captured by methods of other disciplines.

\section{OBJECTIVES}

The major objective of this article is to examine and exemplify the way anthropological perspectives/lens has engaged and dealt with various facets of natural resources management, climate change and global warming.

\section{METHODOLOGY AND CONCEPTUAL FRAMEWORK}

This article is based on secondary data which were obtained from various literatures, books, journals, booklets, articles, websites etc. The conceptual frame 
of the study illustrate the correlation between natural resources management pattern embedded with anthropogenic factors and climate change nexus and the expediency of anthropological lens in evaluating this nexus that leads to actions from quandary.

\section{Natural Resources Management Pattern \& Climate Change Nexus: From Quandary to Actions}

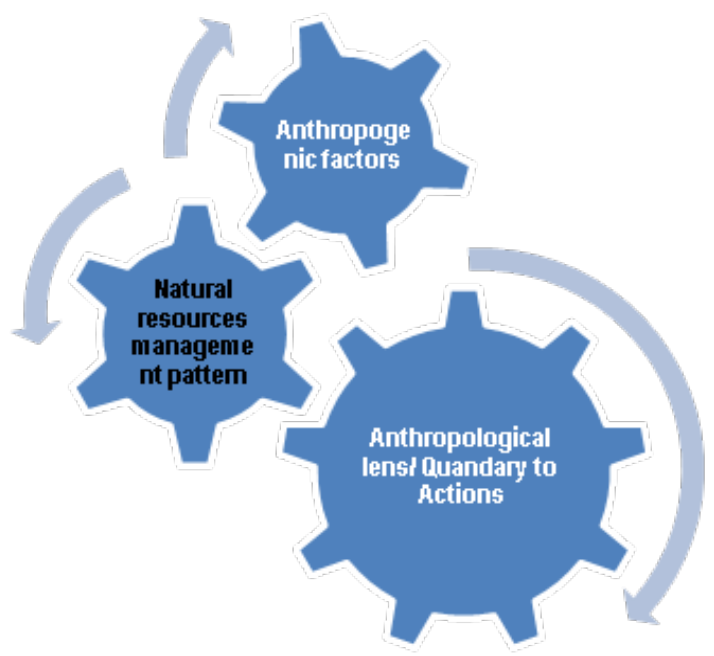

\section{ANTHROPOLOGICAL PERSPECTIVES ON NATURAL RESOURCES MANAGEMENT}

In The Anthropological Lens: Harsh light, Soft Focus (Peacock 2001) has raised the question what is the anthropological perspective? Through what kind of lens does the anthropologist view the world? He inquires does anthropology have just one lens -a single perspective? He forwards the answer that there are as many perspectives as there are anthropologists. The Anthropological Lens throws Harsh light but Soft Focus. Based on photographic metaphors of "harsh light" and "soft focus" anthropological worldview of harsh light denotes a concern with basic reality of human condition, soft focus attempts to grasp all aspects of that condition. Despite multiple perspectives, the four main anthropological perspectives which make is unique among the social sciences include its: cross-cultural or comparative emphasis, its evolutionary/historical emphasis, its ecological emphasis and its holistic emphasis. Cross-cultural or comparative approach avoid equating human nature,-not taking belief or style of behaviour of managing resources for granted in present, studying other cultures with very different understandings of world called defamiliarization. Evolutionary/historical approach focuses upon both biological and cultural evolution of human beings and of human societies-- diachronic that focus upon understanding of and description of patterns of change over time including Natural Resources management (NRM) and climate change that helps to put contemporary society and patterns of social development into an historical context. Ecological anthropology views human societies within the context of larger natural systems- how culture promotes 


\section{Crossing the Border: International Journal of Interdisciplinary Studies}

connections between humans and their occupied ecosystems. Holistic approach closely related to ecological approach focus on human behaviour, society-- incorporating ecology in a significant/integral way with human life, belief that cultures have its own pattern of adaptation to natural resources, stages of adaptation based on major subsistence patterns. Embedded with these vital theoretical perspectives, there are three vital dimensions: the cultural, the institutional and behavioural. The first of these dimensions defines values and expectations concerning resources and environment evolving in any population; the second, the means and ends of key activities; the third, the distinctive patterns of individual need, satisfaction and coping mechanism. Cultural dimensions reckon that Natural resources are socially, culturally ingrained values of community intertwined with human life, behavior, response and way of living, hidden assumptions embedded with social, cultural, cognitive systems rather than technical factors that are clandestinely playing key role in decisively shaping natural resources management pattern. Institutional dimension holds that Resource user's local approaches and skills, founded on traditional cultural concepts of social/cultural institutions act in response to increasing pressures/opportunities in a complex world of commercialization, competition, privatization, westernization of culture and increasing globalization. Behavioural dimension brings its core theoretical tenet that culture frames the way people behave, perceive, understand, experience, and respond to key elements of the worlds which they live in grounded in systems of meanings and relationships that mediate human engagements with natural phenomena and processes. This framing is particularly relevant to the study of climate change and global warming that necessitate movement away from a known past, though an altered present, and toward an indecisive future, since what is recalled, recognized, or envisaged rests on cultural models, norms and values.

Holism is the assumption that no complex entity can be considered to be no more than the sum of its parts, that any given aspect of human life is to be studied with an eye to the way it is / related/ to other aspects of human life. Holism is a synonym for a relational emphasis; an emphasis upon studying the / relationships/ among all aspects of culture-rather than whole cultures. Knowing anthropological facts and weaving them into a coherent synthesis, one still does not grasp the full meaning of the anthropological perspective unless one comprehends cultural significance. One does not grasp the full meaning of the anthropological perspective unless one comprehends cultural significance of any phenomenon. Culture is a part of a broad view of human existence that anthropologist term holistic. If the holistic field of vision of anthropology is extended far enough, it would include the perceiver as well as the object perceived, and this too is a concern of anthropology, which recognizes the subjective as well as the objective aspect of knowledge, human behaviour, cognition and social cultural values that are vital in determining the status of natural resources as they are not only woods but are socially and culturally defined values of local community intertwined with human diverse behaviour and response.

The holistic vision of anthropology is linked to cultures. Bennett (1966) claims that anthropologists use the term culture to refer to distinctive life styles 
associated with particular groups of people. Going according to this, each culture must be considered to have its own pattern of adaptation to the physical environment. These could, in turn, be classified into types or stages of adaptation based on major subsistence patterns: hunting and gathering, pastoralism, settled agriculture, and so on....Within the social sciences, at least, three important dimensions ought to be studied : the cultural, the institutional and behavioural. The first of these defines values and expectations concerning resources and environment evolving in any population with relative social unity; the second, the means and ends of key activities; the third, the distinctive patterns of individual need satisfaction and coping mechanism.... One must know about institutions and precedents in order to determine why people do what they do in particular times and places. The concept of adaptation is central to the human use of the physical environment. It is the change in modes of behaviour designed to manage or improve a lot of the individual and the group. Any change in adaptive patterns in groups usually involves a collective decision. That is adaptation at group level is coincident with social action, interaction, and dynamics of social organization and change. There exists the vitality of social values, institutions and norms/traditions in regulating the environment, indispensability of norms, customs, and traditions in influencing resource user's behaviour on natural resources. Cognitive anthropology known as "ethno science," "ethno semantics" focuses on the native's point of view--- how people in particular cultures classifies the world including their natural resources (Colby 1996). Originally, it is based heavily on how local people use expressions to codify reality in an emic (internal) idealist approach to culture. Here culture is defined as a body of knowledge in people's heads --a mental model, map, or maze way. Thought is culturally shaped while making use of natural resources, not just psychological---people learn to think in certain ways in each culture and each culture is determined by the Indigenous knowledge which is the traditional knowledge of the local people that has been continuing from centuries and which has been given little attention in development planning's based on western knowledge. Ethno conveys a special sense--the system of knowledge and cognition typical of a given ethnic group or community signifying the local knowledge of local people, local people's concept of their natural resources. And where there is the special role of Indigenous knowledge in resource management activities and which prepares the anthropological perspectives in resource management (Sillitoe 1989). The hidden assumptions about culture are embedded in human cultural discourses and resource management institutions. Such assumptions are like lenses-they shape how people perceive social reality. As scholars and managers for anthropologists who are trying to understand conflicts in resource use, it is important to make these lenses visible, that is, to look at a society's cultural lenses rather than through them, to acknowledge, understand, and question the assumptions we have about cultural milieu and its embeddedness with nature. One important point central to this issue is an understanding of the lenses of Culturocentrism that is, taking the dominant culture's experience as the norm, and other culture's experiences as deviations or "other". Also informative are ideas concerning culture polarization, that is, the insidious use of 


\section{Crossing the Border: International Journal of Interdisciplinary Studies}

perceived differences in culture as an organizing principle for natural resources management. Messerschmidt (1991) provided a framework for the study of IK (Indigenous Knowledge) and illustrates it with numerous examples from forestry research in Nepal. The framework is divided into two parts. First, he discusses the collection and understanding of basic IK. This part provides information on the nature of indigenous forest knowledge, which holds the knowledge, where and how the knowledge can be accessed, and what the knowledge means to the people who have it. The second part focuses on the application of IK: i.e. the link between resource management and ethno- knowledge. Examples show that over time indigenous knowledge adapts to changing social, economic and environmental conditions (Gilmour and Fisher 1991).

A cognitive consonance throughout different ethnic groups is a consistency among the beliefs, ideas, perceptions and other items and aspects of knowledge that form a cognitive system such that the system stands as an integrated and harmonious whole without internal contradictions. Identical with it is the tendency of individuals to include among his cognitions those items of knowledge that are in agreement with his beliefs, attitudes, values, and needs and to exclude those that are not. Selectivity occurs in perception, interpretation, and remembering. It is this knowledge, which can be better used for handling various sorts of environmental related natural disasters, climate change and global warming. The effect of disasters depends on the spatial and temporal distribution of population. Given the nature of planet, it is rather difficult to control hazards in actual processes. The solution to plummeting disaster and their impacts is thus to focus on decreasing vulnerability and promoting prevention. The latter can be achieved to some extent by incorporating local knowledge and initiatives into the framework of public policy and decision- making. Natural resources management practices are not solely an economic, administrative, bureaucratic, technical or management activities it is more than involvement, participation and sharing of benefits. There are different social and cultural factors tangled with natural resources management practices. No one can disregard the reality that hidden assumptions about culture are embedded in one's cultural discourses and resource management institutions. These hidden assumptions determine how local people perceive their natural resources, manage and control in the long run. Going against these, means inviting confusions, conflicts and problems, such as deforestation, environmental deterioration, climate change and global warming. Berardi (2002) argues that for the scholars and managers who are trying to understand conflicts in natural resources use, it is important to make the lenses visible. It means to look at a society's cultural lenses rather than through them. Such lenses are relatively easy to see in relation to gender and social/cultural relations/activities which are vital in determining the providence of natural resource management practices, climate change and global warming nexus.

\section{CLIMATE CHANGE, GLOBAL WARMING AND ANTHROPOLOGICAL PERSPECTIVES}

The issue of climate change is more anthropological than environmental. I squabble that there are vital key contributions that anthropology brings to 
understandings of climate change. Human and ecosystem interactions have been a decisive dimension of anthropological theories of what drives culture and behaviour. Climate change is about culture with cultural insinuation, more of the intimate human-environment and nurture-nature relations. Culture is a flexible contingent to the environment with a social unit's characteristics (technology, politics, and modes of subsistence etc) having adaptive limitations. The awareness to the cultural values and political relations shape the production and interpretation of climate change knowledge and shape the basis of responses to ongoing environmental changes. An awareness of the historical milieu that underpins contemporary climate change and global warming debates is furthermore vital. This awareness stems from the interest of both archaeologists and environmental anthropologists in the history of society-environment interactions. Anthropology's broad, holistic view of society and environment highlights the multiple cultural, social, political, and economic changes that are taking place within human society. The political anthropology's concern is for understanding the political factors, policies and implications on climate change. Such dynamics always interact with, and sometimes outweigh climate change as sources of change and need to be understood if public policies are to succeed. I deem that incorporation of anthropological perspectives can lead to a more nuanced understanding of the challenges that climate change poses and to more effective solutions.

Creativity, adaptability, and flexibility are basic human attributes, and human diversity is the subject matter of anthropology. Anthropological knowledge is holistic and holism refers to the study of the whole of the human condition: past, present, and future; biology, society, language, and culture. Anthropology has two dimensions: general and applied. The applied uses anthropological perspectives, theory, methods, and data to identify, assess, and solve social problems including the natural resources management pattern, climate change and global warming. From an anthropological perspective, there are cultural implications of climate change. Climate change is ultimately about culture, for in its wake, more and more of the intimate human-environment relations, fundamental to the world's cultural diversity. For indigenous peoples in the regions of the world, climate change brings different kinds of risks and opportunities, threatens cultural survival and undermines indigenous human rights. The consequences of ecosystem changes have implications for the use, protection, and management of forests, wildlife, fisheries and affecting the customary uses of culturally and economically important species and resources. The effects of climate change are not just about communities' or populations' capacity to adapt and exercise their buoyancy in the face of exceptional change. Climate change is furthermore about the relocations of human, animal, and plant populations to adjust to change and to muddle through with its implications. Such relocations, both actual and projected, necessitate a loss of intimate human-environment relationships that not only ground and substantiate indigenous worldviews, but also work to maintain and guard local landscapes. In some cases, moves end result is the loss of mythological symbols, meteorological orientation and even the very totem and mainstay plants and animals that shape a culture. Indigenous peoples themselves may 


\section{Crossing the Border: International Journal of Interdisciplinary Studies}

argue that, despite having contributed the least to greenhouse gas emissions, they are the ones most at risk from its consequences due to their dependence upon and close relationship with the environment and its resources. Their livelihood systems are often in danger to environmental degradation and climate change, especially as many dwell in economically and politically marginal areas in fragile ecosystems in the countries likely to be worst affected by climate change. Massive changes in ecosystems are occurring and have in many cases been accompanied by opportunistic and often environmentally devastating resource exploitation. To indigenous peoples this means that climate change is not something that comes in isolation; it amplifies previously existing problems of poverty, de-territoriality, marginalization, and non-inclusion in national and international policy-making processes and discourses. Indigenous peoples in Asia and Latin America are facing rapid and overwhelming changes in their societies and livelihood strategies, making them mainly vulnerable to climate change, poverty and other forms of marginalization and exploitation. ILO (International Labour Organization) convention No. 169 recognizes the survival of indigenous peoples - as distinct peoples - largely depends on the sustainable utilization of their traditional lands and natural resources in a manner and mode appropriate to their specific circumstances and survival.

Directly or indirectly human activities alters the composition of the global atmosphere and which is in addition to natural climate variability observed over comparable time periods. However, there are numerous uncertainties in understanding a complex system like Earth's climate. Crate and Nuttall (2009) squabble that the term climate change refers to the contemporary phenomena of anthropogenic global climate change, as distinct from natural climate variability. It may not be just a temperature, but also includes factors such as humanity, precipitation, cloudiness, and winds. The variations in climatic parameters are attributed directly or indirectly to human activities. It is increasing the hazard of deforestation, flooding, storms, desertification, soil erosion, and sea level rise contributing to international and national migration with the experiences of privation, loss of jobs and homes, and the fragmentation of families, communities and different types of social, cultural and political upheavals. Hence, the impact of climate change is not consistent across the globe, and considerable differences can be perceived between different regions, places and communities. The potential risk of vulnerability to climate change is expected to be high in mountains and the coastal areas of the sea- the island countries (Dessler and Parson 2006). The cultures of rural native peoples worldwide are at the mercy of climate change. Local infrastructure and material culture - those tangible aspects of culture such as artifacts, architecture, and art - are constructed with locally-available natural resources now being threatened. It is also doable that non-tangible facets of culture such as customs, stories, myths, and songs, as well as entire languages tied to a culture's place of origin, will face extinction. This is owing to the possibility of increasingly uninhabitable rural locations forcing members of rural cultures into urbanized environments, thereby breaking ties to homelands. The threat is not so much a consequence of indigenous peoples' inability to acclimatize to distur- 
bances in climate, but rather their vulnerability to such rapid changes to which adjusting would require much more time for preparation and less frequency between turbulences. Dessler and Parson (2006) argue that 'climate change' does not just affect people directly; it also affects all other environmental and ecological processes, including many that we might not recognize as related to climate change. The risks of climate change for least developed countries like Nepal can hardly be exaggerated and communities, governments and other institutions have lot of functional challenges to minimize the adverse effects of climate change. In Nepal there are plausible bodies of substantiation based on various researches that climate is changing and that these changes are in large part caused by human activities with cultural implications (Upadhyay 2007). The cultural implications could be similar to the disorientation, alienation, and loss of meaning in life that happens when any indigenous people are removed from their environment of origin owing to impacts of climate change. With the change in environment, it is vital to comprehend the cognitive impact and cultural implications to a people's sense of native soil and place. The relationship of native communities with local resources, livelihood along with their socio-economic characteristics and climate change stands imperative. With the increasing deforestation many of the indigenous groups such as the Rautes in Nepal are confronting with food scarcity and are moving away from their traditional homeland. Dahal (1983) argues that it is vital to understand the socio-economic and demographic characteristics of a community in relation to its available resources. Maharjan (2002) bicker that being an economically less developed agricultural country, the relationship between Nepalese agricultural system, livelihood, and livestock and forest remains crucial, hence a nexus between natural resources management pattern and climate change. Temperature and rainfall are two important climatic factors affected by climate change in general and global warming in particular which is rapidly advancing and responsible for creating widespread threat. Human-made factors such as deforestation, agriculture, industries, automobiles, and the burning of fossil fuels, are contributing to GHG (Greenhouse Gas) emission which is the foremost and most vital cause of global warming and rising temperature that is creating different problems on ecosystems and biological behaviors of different species. In the Nepalese Himalayas glaciers are particularly susceptible to changing temperatures. Warmer temperatures cause accelerated melting of glacial ice, resulting in shrinkage of glaciers. This can lead to the formation of glacial lakes, some of which may burst out and cause flash floods known as glacial lake outburst floods (GLOFs) downstream in the valleys. Khumbu glacier in Nepal has retreated about $100 \mathrm{~m}$ on average annually since 1953 (Shrestha et.al. 1999). There are still at least 20 glaciers in Nepal that are likely to outburst in next 5-10 years (Iyngararasan et. al. 2002). Cruikshank (2005) draws some important lessons for the pursuit of defining anthropology's role in climate change. Specifically she emphasizes how glaciers, previously considered eternally frozen, largely inert, and safely distant, gain new meaning in the context of contemporary climate change concern. Cruikshank stresses how glaciers undergoing rapid environmental change are interpreted differently. In the Andes, a long-held ritual practice 
involving pilgrims carrying pieces of glacier away has recently stopped to prevent the glacier's diminishing. There are contrasting approaches to understanding climate change and they all deserve attention and consideration as we approach strategies and solutions. Climate change exacerbates existing social, economic, political, and environmental trends, problems, issues, tensions, and challenges and hence increases vulnerability of different regions. Various districts of Nepal are at high risk to climate change consequences including capital Kathmandu.

\begin{tabular}{|l|l|}
\hline \multicolumn{1}{|c|}{ Vulnerability ranking } & \multicolumn{1}{|c|}{ Districts } \\
\hline Very high (0.787-1.000)- & $\begin{array}{l}\text { Kathmandu, Ramechhap, Udayapur, Lamjung, Mugu, } \\
\text { Bhaktapur, Dolakha, Saptari, Jajarkot, }\end{array}$ \\
\hline High (0.61-0.786)- & $\begin{array}{l}\text { Mahottarai, Dhading, Taplejung, Siraha, Gorkha, } \\
\text { Solukhumbu, Chitwan, Okhaldhunga, Achham, Manang, } \\
\text { Dolpa, Kalikot, Khotang, Dhanusha, Dailekh, Parsa, Salyan, }\end{array}$ \\
\hline Moderate (0.356-0.600)- & $\begin{array}{l}\text { Sankhuwasabha, Baglung, Sindhuli, Bhojpur, Jumla, Mus- } \\
\text { tang, Rolpa, Bajhang, Rukum, Rauthat, Panchthar, Parbat, } \\
\text { Dadeldhura, Sunsari, Doti, Tanahu, Makawanpur, Myagdi, } \\
\text { Humla, Bajura, Baitadi, Bara, Rasuwa, Nawalparasi, Sarlahi, } \\
\text { Sindhuplachok, Darchula, Kaski }\end{array}$ \\
\hline Low (0.181-0.355)- & $\begin{array}{l}\text { Nuwakot, Dhankuta, Kanchanpur, Bardiya, Kapilbastu, } \\
\text { Terathum, Gulmi, Pyuthan, Surkhet, Argakhachi, Morang, } \\
\text { Dang, Lalitpur, Kailali, Syangja, Kavrepalanchok }\end{array}$ \\
\hline Very low( 0.000-0.180)-- & Ilam, Jhapa, Banke, Palpa, Rupandehi \\
\hline
\end{tabular}

Source: NAPA document (2010)

Declining yield due to unfavourable weather and climate lead to vulnerability in the form of food insecurity, hunger and shorter life expectancies and poor will again be the victim. Hydro-electricity accounts for about $91 \%$ of total power production in Nepal, hence Nepali people living in different parts will have to face problems of severe electrical power-cut due to sediments carried along the floods. By the use of anthropological lenses not only in local context but on the scale of global geopolitics, anthropologists perceive the causes and effects of climate change to be about people and their life, power, ethics and morals, environmental costs and justice, and cultural and spiritual survival. Addressing the issues of equity and justice implications of climate change seems imperative. Climate change is proving ecological colonialism with extensive social, cultural, political implications, the result of global processes that were neither caused nor can be mitigated by inhabitants of majority of climate-sensitive regions now experiencing the most unprecedented change. Native peoples and place-based peoples find themselves at the mercy of and having to adapt to changes beyond their control.

\section{USES OF ANTHROPOLOGICAL LENSES}

Anthological lens are manifold but crucial in studying the impacts of the science of climate change and structured climate change refutation on popular understandings of global warming. How is climate science disseminated and received by global viewers, through which channels, and with what effects? What facets of climate science appraisal are adopted and integrated with local knowl- 
edge and under which conditions? Anthropologists treat climate science as a communicable object. By use of anthropological lenses on global geopolitics, anthropologists perceive causes and effects of climate change to be about people , their life, power, political economy, ethics, morals, environmental costs, justice, cultural-spiritual survival, equity and justice.

Societal transformations often correspond with climatic alterations, although shifts in climate systems do not always result in significant changes in society. One of the remarkable impacts of climate change is on the people of the world, as changes in climate have both facilitated and restrained human geographic movement. Additionally, climate has played a role in the collapse of social systems and contributed to the limited human use and reconstruction of physical environments, allowing subsequent re-occupation. Throughout the countries of the globe, Anthropologists increasingly have been active in documenting the special challenges, lived experiences, local knowledge, and perceptions of contemporary anthropogenic climate change in human communities, especially in developing settings that are hardest hit but least involved in the production of greenhouse gases. Anthropologists are appraising concepts like hazard, vulnerability and resilience in examining the sustainability of local ways of life and resource utilization. Among medical anthropologists, a topic of apprehension is the health implications of global warming, including its impacts on the spread of vectors, flooding tied to sea level rise and melting glaciers, wind-blown soils and microbes, and the infrastructural damage to health-related resources of climate change. Anthropologists are working on identifying the assortment of factors that influence how and why communities react as they do to climate change, including initiating adaptive responses, politically organizing to demand striking slash in global greenhouse gas emissions, seeking outside assistance to adjust to growing threats, fleeing deteriorating conditions, and expressing a lack of capacity to take action meaningfully to changes that are occurring. All of these issues are outside the domain of expertise of other sciences and involve issues of culture and social structure. Anthropological connection is vital in appraising the social origins of climate change in light of the intensification of global economic system's dependent on profit-making and unequal distribution of wealth, continual resourcedepletion, and mounting waste producing economic expansion. This issue too is beyond climate science in that how human societies perceive and treat their environments, how they organize their use of energy, and the systemic drivers of massive quantities of greenhouse gas production and emission are embedded in social not environmental systems. This recognition has drawn anthropologists to debates on issues like societal collapse and even to the topic of economic collapse on a splendid scale. Anthropologists have commenced to draw attention to the interaction of climate change with a substantial list of other anthropogenic environmental transformation and ecological crises. Rather than a separate threat, global warming is but one of multiple consequences of human restructuring of earthly ecosystems especially natural resources. Anthropological ethnographic knowledge inspect the making of climate science as an arena of human behavior enlightening the ways the wider political environment, including aggressive 


\section{Crossing the Border: International Journal of Interdisciplinary Studies}

climate change denial campaigns, have caused climate scientists to be observant in their presentation of their findings to public audiences. The key dilemma is communicating with both masses and policy makes in culturally meaningful and effective ways. Anthropological lens are vital in investigating the social origins and economic motivations of climate change rejection and the social ideologies and motivations of climate change rejecters. Given the triumph of the rejecters in embroiling confusion about global warming and in holding up meaningful policy responses to crises, gaining a clear understanding of climate change denial and dissemination of knowledge is of critical significance for anthropologists.

\section{FROM QUANDARY TO ACTIONS}

Adaptation is mainly about warning people about certain events in advance and preparing them to deal with vulnerability and uncertainty. Increasingly, anthropologists are encountering the local effects and broader social, cultural, economic, and political issues of climate change. Wherever they go and work, they encounter local people (who are the worst victim) telling similar accounts of the changes they notice in the weather and climate and how they became the innocent victim of climate change-paying for the consequences of the blunder committed by others at global level. Anthropological lens respond to climate change at the local, regional, national, and global scales and are helpful in reflecting the understandings in application and seeking ways to collaborate with communities to assist them in addressing their climate change concerns or in bridging the science-community dissection with a notion that climate change issues have to be dealt, comprehend, and resolved within a context of the interplay of multiple stressors at all levels-- local to global, national to international. Human activities, industrial development, consumerism, resource-use regulations, and global economic processes have far-reaching consequences for the environment and on indigenous and local livelihoods. Native and local economies are not self-reliant blocked systems, and although their involvement in global networks of production and consumption may offer opportunity to strengthen and extend their possibilities, it also introduces greater elements of risk and perhaps makes people and their livelihoods less durable to coping with and adapting to climate impacts. For some people, climate change may not be the most immediately pressing issue facing them. Social, cultural, and economic change often has more immediate effects. Communities differ in the way they perceive risk, in the ways they utilize strategies for mitigating negative change, and in the effectiveness of local adaptive capacity. The impacts of climate change are speeding up the adoption of different subsistence and local economic strategies to suit new ecosystem regimes or, with more rapid change, the displacement and resettlement of peoples who risk at risk or even losing their homeland to environmental change.

In coping climate change menace, there are diverse bizarre rituals that are common among the farmers of Nepal as different beliefs exist among them. Among the Tharu community on the bank of the Babai River near Gularia during the prolonged drought conditions they perform bizarre rituals. During the rituals Tharu women plough their house yard in a reverse manner at night sing- 
ing song to appease rain god when dry spells persist too long effecting agriculture. Husbands are blindfolded, and if any of them are peeping, they are punished and fined foodstuff, which is again offered to the rain god. The punishment may also include the dressing up of the males in female attire. Tharu communities also worship frogs as a part of the rituals (Bhandari 2005). The Tharu women of western Nepal do rain-dance naked to produce rain (Upadhyay 2007). Although there is no scientific logic of naked dance, however, it bring people together and reaffirms their faith in the collectivism, and thus the rain dance of Tharu has the function of promoting social solidarity that will help the society cope with the drought. The same prevails in the rite de passages of different ethnic groups of Nepal and other countries. The month of Shrawan (July-August) is not the right month for marriage in Nepal; however, Adhikari (2009) reports the marriage ceremony of frogs at Sijuwa in the Morang district as the farmers in the region were worried due to the total absence of rain. Invitation card was distributed to about 1500 persons for the marriage ceremony of Meghnath from Kohabara to Sulochana from Sijuwa. The ceremony was complete in all respect conducted by a priest that was held on the fourth of Shrawan. The male frog was named Meghnath meaning 'lord of cloud'. Sulochana is the wife of Meghnath in Purana, a Hindu epic. The report, however, does not provide information whether the rituals was a success or failure to appease the rain god. Local institutions are effective/legitimate means of controlling and regulating climate change. There are various socio-cultural practices commonly known as riti-thiti systems among the Tarami Magar of western Nepal (Gurung 1996). Socio-cultural practices are effective/appropriate for managing local resources in the changing context of climate change. The influence of religious beliefs and rituals give rise to appropriate institutions and organizations for cooperative resources management and provide messages and symbols for nature conservation.

Climate change has got ultimate and historical to present direct interrelationship with human culture having impacts on culture, ways of life, spirituality, and in other arenas that are not obvious. Based on anthropological lenses it is explicitly noticeable that climate and culture/environment and society are inextricably linked, as opposed to the traditional natural science approach that does not deal with humans. Local people's experiences range broadly from erratic weather patterns, ecological variability and their bad effects on human health. However, globally local people are still not quite sure whether the changes are due to climate change or some other reasons. Effective perceiving, understanding, experience, and response, predictability, awareness, provision of certain support systems and better planning are some of the key issues to consider in local preparedness for reducing vulnerability and enhancing resilience.

Culture frames the way people perceive, understand, experience, and respond to key elements of the worlds which they live in (Roncoli et.al. 2006). It is needed to be attentive to considerations of human agency and different responses and strategies in any one particular locality, as well as to local and regional scales, organizational complexity, ideology, technology, and social and cultural values of local populations within an interregional context. The cultural framing is 


\section{Crossing the Border: International Journal of Interdisciplinary Studies}

grounded in system of meanings and relationships that mediate human engagements with natural phenomena and global political processes. Crate (2009) says that civil society and self advocacy (including anthropologists) are some where playing proactive roles as communicators by seeking out the local, regional, and national channels through which local voices can affect any forms of policies. Here, the notion of the construction of social reality and the embeddedness approach, in understanding and analyzing individual human behaviors, their institutions, human-environment relation, micro-macro structural relations, and others, is important part of resolving the discrepancy between agency and structured based approaches. It means the understanding of the concept emphasizes the needs of understanding social networks patterned in the dynamics of human and institutional interactions. He further says that people in communities talk to each other and to outsiders about particular risks, and that is what creates their meaningful, action-prompting perceptions on the emerging risks. Crate (2009) says that global climate change is caused by the multiple drivers of our global consumer culture, transforms symbolic and subsistence cultures, and will only be forestalled via a cultural transformation from degenerative to regenerative consumer behavior. The human agency and their adaptability in changing context are to develop their own sense of impact of climate change in human societies. The variation of the size, scale of organization, social differentiation, subsistence activities, productive strategies, ideologies, and worldviews play the important roles in this regard. The way how they are maintained, reproduced, and transformed as a result of the impact of day to day practices by individuals who are constrained by their perceptions, beliefs, norms, values and mind sets as cognitive schemata and are outcomes of their either positive or negative perceptions. There are immediate and long-term consequences of climate change and the existing attempt at greening of politics of remedying the potential catastrophic consequences aim to remedy the shortsighted modus operandi of societies. A long term vision will be more effective for tackling the menace. The relationship of local communities with local natural resources, bio-diversity, and livelihood along with their socio-economic characteristics stands vital. When the particular community has access to information about how climate change is affecting their lives, often in tandem with seeing changes to their lands, then they act accordingly against the impacts in their life ways. Nuttall (2005) argues that the adaptation to extreme climate events will be a measure of ability or inability of individual, household, and communities to make decisions that allow them to respond effectively and with a degree of autonomy. He further argues that it is challenge to understand climate change within a broader context of political processes and ambition, cultural specificity, and people's epistemological, social, cultural, economical and moral relationship with the environment. The arguments of Puntenney (2009) may be interconnected herewith. He says that upon closure examination of the issues surrounding climate change, we know by definition that the outcomes of international debates are the result of complex interactions of many factors, including sudden changes in the global environment or scientific understanding, macroeconomic trends, domestic and international political environments, and 
the presence or absence of effective leadership. Bohren (2009) based on the car culture in USA concluded that transformation in the ethos of individualism, personal freedom, and mobility away from reliance on the car as cultural challenge of technological and behavioral components of emission reduction. The query is how discourses of global climate change politics interrelated with local socioeconomic dynamics and discourses.

\section{CONCLUSION}

Perceiving the challenge that climate change poses and crafting appropriate adaptation and mitigation mechanisms requires input from the breadth of the natural and social sciences. Anthropology's in-depth fieldwork methodology, long engagement in questions of society-environment interactions and broad, holistic view of society yields valuable insights into the science, impacts and policy of climate change. Yet the discipline's voice in climate change debates has remained a relatively marginal one until now. In this article I identified key ways that anthropological knowledge/lens can enrich and deepen contemporary understandings of climate change. From discussions allied to natural resources management practices it construed the conclusion that natural resources management practices are being impacted from factors like cultural, community and societal activities and on turn these activities are anthropogenic factors responsible for climate change calling for the equity and justice implications of climate change issue. Climate change is ecological colonialism at its fullest development-its critical scale-with sweeping social and cultural implications. Anthropological lens seek to respond to climate change at the local, regional, national, and global scales and are helpful in reflecting the understandings in application and seeking ways to pool resources with communities to assist them in addressing their climate change concerns or in bridging the science-community dissection---understanding and analyzing individual human behaviours, their institutions, human-environment relation, micro-macro structural relations, and others, is important part of resolving the discrepancy between agency and structured based approaches, and in the process cultural structural change does play vital role in altering human activities, social and natural resources management pattern etc. Discernibly, society is changing in terms of social, cultural, educational, religious, and other aspects from very beginning because society keeps changing but its volume differs. So, definitely it is easy to understand the situation of local people who are users of their respective natural resources and the reasons why they are in organized position as well as their snags too. Conventional values of culture determining natural resource user's participation in decision making, implementation about natural resources management need exertion on some complicated linkage between intensely sensed climate change, cognitive, cultural values need of natural resources users. The natural resources management pattern unswervingly influences the climate change and global warming which is not only a menace for Nepal, but a global threat, however owing to uncontrolled human activities, lack of local awareness, low economic and social status, effective integrated planning and policy it is difficult to ensure the 


\section{Crossing the Border: International Journal of Interdisciplinary Studies}

success of climate change program in Nepal and other least developed countries. It is necessary to break this tendency, and thereby reach long lasting success in the field of climate change through appropriate strategy and use of a wide range of technical and non-technical human resources in an active collaboration with local people, developing adaptation and coping strategies with the approach which is holistic, with a strong emphasis on community participation by linking the impacts of climate change with the promotion of improved livelihood options such as infrastructures, conservation of water sources, pastureland and community forests. This can be accomplished by providing rural people with alternative energy sources, such as biogas, solar power, and hydroelectricity and by adopting better land use management to improve carbon sinks. Pedestal on a people-centric model, with an effective people oriented plan, it is imperative to empower and make capable the populace to operate and maintain their sustainable existence in a sustainable natural milieu. Microanalyses of risk management and decision-making approaches can bring science and policy closer to needs of vulnerable via communication of climate information by ensuring consistency with local knowledge frameworks and even integrating indigenous knowledge with modern scientific knowledge. Lets' Jointly, Raise The Voice, Not the Sea Level and Denial Activities of Climate Change.

\section{REFERENCES}

Adhikari, S. (2009). “The Big 'O”. Kathmandu, The Himalayan Times. 7:7.

Berkes F \& Farvar.T. (1988). Common Property Resources. Ecology and community based sustainable development. London: Belhaven press. Pinter publishers. Bennett, J.W. (1996). Human Behaviour: Essays in Environmental and development Anthropology. London: Transaction Publishers, U.K.

Berardi, Gigi. "The lenses of culture in natural resource management: Discussion paper". Paper prepared for the cultural aspects of caring/cultural construction of nature ISSRM, Bellingham.

Bhandari, D. (2005). "Weird Rituals to Appease rain God". Kathmandu, The Himalayan Times.

Boko, et.al. (2007). "Africa: Climate change 2007: Impacts, adaptation and vulnerability”. Contribution of Working Group II to the Fourth Assessment Report of the Intergovernmental Panel on Climate Change, M.L. Parry, O.F. Canziani, J.P. Palutikof, P.J. van der Linden and C.E. Hanson, Eds., Cambridge University Press, Cambridge UK.

Bohren, Lenora. (2009). "Car Culture and Decision Making: Choice and Climate Change”. In: Crate, Susan A.; and Nutall Mark ed. From Encounters to Actions. Walnut Creek, California, Left Coast Press, Inc.

Colby, Benjamin L. (1996). "Cognitive Anthropology”. In David Levinson \& Melvin Ember (ed.). Encyclopaedia of Cultural Anthropology, Vol. 1, Henry Holt, USA.

Crate, Susan A. and Nuttall, Mark. (2009). From Encounters to Actions. Walnut Creek, California. Left Coast Press, Inc.

Cruikshank, J. (2005). Do glaciers listen? Local knowledge, colonial encounters, and 
social imagination. Vancouver: UBC Press.

Dahal, Dilli Ram. (1983). Poverty or Plenty: Innovative Responses to Population. Unpublished PhD dissertation submitted to University of Hawaii.

Dessler, Andrew E. and Parson, Edward A. (2006). The Science and Politics of Global Climate Change: A Guide to the Debate. Texas A \& M University, University of Michigan, Ann Arbor.

Geertz, C. (1963). Agricultural Involution: The process of Ecological Change in Indonesia. Berkeley: University of California Press.

Gilmour, D.A. \& Fisher, R.J. (1991). Villagers, forests and foresters: the philosophy, process and practice of Community Forestry in Nepal. Sahayogi Press, Kathmandu, Nepal.

Gurung, O.P. (1996): Customary Systems of Natural Resource Management among Tarami Magars of Western Nepal: Unpublished PhD Dissertation, submitted to the Faculty of Graduate School Cornell University, Ithaca, New York.

Iyngararasan, M.L., Tianchi, L. \& Shrestha, S. (2002). “The Challenges of Mountain Environments: Water, Natural Resources, Hazards, Desertification and the Implications of Climate Change". Draft Background Paper E1 for the Bishkek Global Mountain Summit.

Maharjan Keshav L. (2002). Community participation in forest resources management in Nepal. Graduate School for International Development and Cooperation, Hiroshima University, Higashi-Hiroshima, Hiroshima, Japan.

Messerschmidt, D.A. (1991). "The uses of anthropology in agro / social forestry R \& D: Approaches to anthropological forestry" in Burch R \& Parker J (Eds.), Social Science applications in Asian Agro forestry. New Delhi: Oxford and IBH Co. Pvt. Ltd., for Winrock International.

NAPA. (2010). Government of Nepal, National Adaptation Programme of Action (NAPA) to Climate Change. Kathmandu: Ministry of Environment.

Nuttall Mark (2009). Anthropology and Climate Change. Left Coast Press, Inc., ed, USA.

Nuttall et.al. (2005). "Hunting, herding, fishing and gathering: Indigenous peoples and renewable resource use in the Arctic". In ACIA, Arctic Climate Impact Assessment: scientific report. Cambridge: Cambridge University Press.

Ostrom, E. (1990). Governing the commons: the evolution of institutions for collective action. New York: Cambridge University Press.

Peacock James L. (2001). The Anthropological Lens: Harsh light, Soft Focus. Second edition, Cambridge university press, United Kingdom.

Puntenney, P. J. (2009). "Where Managerial and Scientific Knowledge Meet Socio-Cultural Systems: Local Realities, Global responsibilities”. In: Crate, Susan A.; and Nuttall Mark (ed.) Anthropology and Climate Change. Left Coast Press, Inc., USA.

Roncoli, C. (2006). "Ethnographic and participatory approaches to research on farmers responses to climate predictions". California, Climate Research, 33:1.

Shepherd. G. (1992). "Managing Africa’s tropical dry forests: a review of indigenous methods". Agricultural Occasional Paper 14. Overseas Development Institute, London, UK. 
Shrestha, A. B., Wake, C. P., Mayewski, P. A. \& Dibb, J. E. (1999). "Maximum Temperature Trends in the Himalaya and its Vicinity: An Analysis Based on Temperature Records from Nepal for the Period 1971-94." Journal of Climate, 12:9. Climate Change Research Center, Institute for the Study of the Earth, Oceans, and Space, University of New Hampshire, Durham, New Hampshire. Silitoe, Paul. (1989). The Development of Indigenous Knowledge: A New Applied Anthropology. Current Anthropology Publications, 39(2). The University of Chicago Press on behalf of Wenner-Gren Foundation for Anthropological Research.

Upadhyay, Prakash. (2007). User groups participation in community forest resources management in western Nepal. Unpublished $\mathrm{PhD}$ dissertation in Anthropology, TU, Kirtipur.

Vogel, C., S. Moser, R. Kasperson, and G. Dabelko. (2007). "Linking vulnerability, adaptation, and resilience science to practice: Pathways, players, and partnerships". Global Environmental Change, Vol-17.

\section{ABOUT THE AUTHOR}

Dr. Prakash Upadhyay is an Associate Professor in Anthropology at Tribhuvan University, Prithvi Narayan Campus, Pokhara, Nepal. He is teaching for the last eighteen years. He has been teaching to Master level students. He is trained in Denmark where he had been a research fellow. He holds a Doctoral degree (PhD) in Anthropology and also research work equivalent to Post Docs. He has also got to his credits five Masters Degrees in five different disciplines-M.A. in Anthropology, M.A. in English literature, M.A. in History, M.A. in Economics and M.A. in Political Science. He has got to his credits more than 160 research articles and two dozen books published nationally and internationally. His areas of research interests include natural resources management, gender, development and conflict issues. Email:prak-socio@hotmail.com 